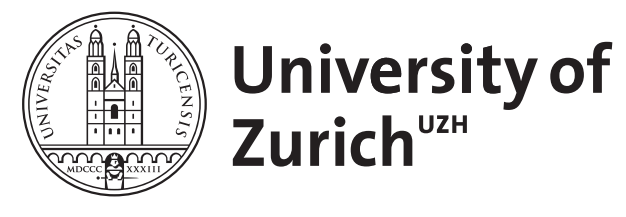

\title{
Human freedom and enhancement
}

\author{
Heilinger, Jan-Christoph ; Crone, Katja
}

\begin{abstract}
Ideas about freedom and related concepts like autonomy and self-determination play a prominent role in the moral debate about human enhancement interventions. However, there is not a single understanding of freedom available, and arguments referring to freedom are simultaneously used to argue both for and against enhancement interventions. This gives rise to misunderstandings and polemical arguments. The paper attempts to disentangle the different distinguishable concepts, classifies them and shows how they relate to one another in order to allow for a more structured and clearer debate. It concludes in identifying the individual underpinnings and the social conditions of choice and decision-making as particularly salient dimensions of freedom in the ethical debate about human enhancement.
\end{abstract}

DOI: https://doi.org/10.1007/s11019-013-9479-z

Posted at the Zurich Open Repository and Archive, University of Zurich

ZORA URL: https://doi.org/10.5167/uzh-172006

Journal Article

Published Version

Originally published at:

Heilinger, Jan-Christoph; Crone, Katja (2014). Human freedom and enhancement. Medicine, Health Care and Philosophy, 17(1):13-21.

DOI: https://doi.org/10.1007/s11019-013-9479-z 


\title{
Human freedom and enhancement
}

\author{
Jan-Christoph Heilinger $\cdot$ Katja Crone
}

Published online: 22 March 2013

(C) Springer Science+Business Media Dordrecht 2013

\begin{abstract}
Ideas about freedom and related concepts like autonomy and self-determination play a prominent role in the moral debate about human enhancement interventions. However, there is not a single understanding of freedom available, and arguments referring to freedom are simultaneously used to argue both for and against enhancement interventions. This gives rise to misunderstandings and polemical arguments. The paper attempts to disentangle the different distinguishable concepts, classifies them and shows how they relate to one another in order to allow for a more structured and clearer debate. It concludes in identifying the individual underpinnings and the social conditions of choice and decision-making as particularly salient dimensions of freedom in the ethical debate about human enhancement.
\end{abstract}

Keywords Ethics of human enhancement · Freedom · Autonomy $\cdot$ Self-determination $\cdot$ Coercion

\section{Introduction}

The moral debate about biotechnological interventions to improve human properties and abilities ("human enhancement") includes a number of competing ethical standards of

\section{J.-C. Heilinger ( $\square)$}

Centre for Ethics (UFSP Ethics and Institute for Biomedical Ethics), University of Zurich, Pestalozzistr. 24,

8031 Zurich, Switzerland

e-mail: heilinger@ethik.uzh.ch

\section{K. Crone}

Department of Philosophy, University of Mannheim, L9, 5 (EG), 68161 Mannheim, Germany

e-mail: kcrone@mail.uni-mannheim.de assessment: considerations of justice come up alongside risk assessments, as do arguments from maximizing utility or deontological and anthropological arguments. The freedom of persons in particular figures prominently in these ethical debates, for example when it comes to assessing the implications of enhancing mental abilities with regard to an individual's range of available options for acting, the possibility of autonomous self-determination or her authenticity.

Yet a closer look at the debate shows that arguments resting on the concept of freedom are by no means a homogenous group. To the contrary: the proponents of both enhancement techniques and of biotechnological abstinence, as well as those who position themselves between these two poles, use the concepts of freedom-and closely related concepts like autonomy and authenticity-to explain and justify their respective assessments. In many cases the arguments even mirror one another with shifting moral valence: whereas the one side claims the availability of biotechnological means of improvement has increased individual freedom, the other side seeks to show that in fact the opposite is true, that it minimizes freedom. This puzzling and often confusing situation leads us to ask what conceptual presuppositions are being made by each of these often contradictory justifications and which aspects of freedom they centre on.

In this paper we attempt to identify those dimensions of the complex notion of freedom that are particularly salient in the debate about human enhancement. In order to achieve this aim we start by analysing and discussing different ways of appealing to the issue of freedom in the enhancement debate-with its different dimensions of range of options, degrees of coercion, self-determination and authenticity. First (1) we describe the central lines of argumentation taken by both the proponents and opponents of biotechnological interventions, and then (2) point to a 
striking symmetry in the organisation of these arguments. Next (3) we turn to the question of whether one can legitimately speak of a unified conception of freedom within the enhancement debate, or whether one needs to draw distinctions that ultimately make it impossible to bring all the different uses of the notion of freedom under a common denominator. We conclude (4) by arguing that it is necessary to clearly distinguish the different understandings which are subsumed under the umbrella notion of "freedom" and identify those related to the individual underpinnings and the social conditions of choice and decision-making as particularly important in the current ethical debate.

\section{The function of "freedom" in the enhancement debate}

The normative debate about "human enhancement" centres around the question of how to morally evaluate when humans "improve" themselves with the help of biotechnological interventions. These improvements include psychopharmaceutical interventions to optimize cognitive abilities or emotional moods, but the term "enhancement" is also frequently used to refer to modifications to the human genome, technological changes to the brain, and invasively equipping the human organism with technological devices.

This ethical question obviously involves conceptual difficulties as well: what exactly is "enhancement"; how can the concept be precisely defined in view of the diversity of possible interventions? Does it refer to a single unified phenomenon at all (Bostrom and Savulescu 2009)? Are there "natural" limits that are inherently valuable (Agar 2010; Parens 1995)? We do not intend to discuss these questions here. We will make use of a minimal definition and take enhancement measures to be intentional, positively assessed biotechnological interventions in the human organism that serve the goal of either producing certain qualities or optimizing extant abilities (Heilinger 2010).

In the following we focus on a particular aspect of the enhancement issue: the connection between enhancement interventions and human freedom. We do not aim to answer the overarching question of which standard of assessment is best suited to normatively evaluating acts of enhancement. Rather we assume that no single general normative theory-such as utilitarianism or deontologyand no single criterion-such as the calculation of harm and benefit or the characterization of the "natural" state of humans-are sufficient for such evaluation. We hold that the mixture of evaluative approaches in the ethical discussion, which compete with each other to some extent and complement each other to some extent, is suited to the complexity and novelty of the problem.
Yet it is striking that so-called arguments from freedom seem almost indispensable to any assessment of enhancement interventions. There seem to be several reasons for this: biotechnological interventions to improve individual abilities are always actions, which as such can be performed freely or under coercion. Since these biotechnological interventions are generally medical measures which frequently can only be performed by experts (e.g. surgical interventions), the decision for or against undergoing such interventions is subject to the condition of free and informed consent. Moreover enhancement techniques often aim to change abilities that can in turn have repercussions for the exercise of individual freedom. How a person decides and the criteria used in reaching the decision depend essentially on emotional, cognitive and volitional conditions that can be changed with the help of biotechnological methods. And in addition, the repercussions of enhancement measures on the autonomy of conduct often affect not just the isolated agent who decides in favour of a certain intervention, but also the social environment as well, since decisions are always made within a social space.

Here we can already see that the issue touches upon various dimensions of freedom. The philosophical discussion of semantic distinctions has a long tradition (Kane 2003). ${ }^{1}$ It is typical to distinguish between a positive and a negative definition of the concept of freedom (Berlin 1969). In its negative sense "freedom" refers to the absence of inner or outer compulsion, which is usually expressed by the term "freedom of action". The positive concept of freedom in contrast refers to persons' abilities to make decisions independently of what has been previously given and thus corresponds to the meaning of "freedom of the will". This second understanding is closely connected to and partly overlaps with the concept of "autonomy", which describes the ability to determine and control one's choices and actions (Christman 2011). Such fundamental distinctions are helpful but lead to the question of which aspects of freedom the various debates focus on and take as premises. Without presupposing any rigid definition of human freedom ourselves, we will begin with an overview of various arguments and types of argument found in the discussion that draw on different varieties of the notion of freedom in their central statements.

\footnotetext{
1 In the philosophical debate the words "freedom", "liberty", and "free will" are used rather as interchangeable. The conceptual distinctions made are independent of the terminology chosen. Attempts to introduce substantial distinctions between "liberty" and "freedom" were unsuccessful. Cf. Carter 2012.
} 
Arguments for enhancement: preserving or expanding freedom

It stands to reason that arguments in favour of the use of enhancement techniques would make use of the concept of freedom. Firstly, the semantics of "improving individual abilities" seems to already imply the notion of freedom: in improving oneself, one 'frees' oneself, it would seem, from (naturally) given limitations. And secondly, the availability of such improvements constitutes "additional" possibilities for actions and decisions.

$(+1)$ One argument emphasizes that the mere availability of biotechnological procedures of improvement expands the individual's options. The biotechnological procedures, insofar as they are available, are actions that the individual can $o p t$ for. This general characterization on its own does not require any consideration of the consequences or intended goals of the actions in question. When an individual gains access to medical measures such as neurosurgical interventions or pharmaceuticals, these measures as such present the individual with additional options for action (Bostrom and Sandberg 2009). The central premise here is that a larger number of possible actions means an expansion of the individual freedom of action. It could be objected that the principle conflates quantity and quality in a manner that is problematic or at least needs justification: an expansion of our options-such as is promised by the advertising for consumer products, for example_at most suggests greater freedom. Yet we are merely given the pretence of alternatives. However, such general worries could be met with examples from other areas and other analogies, such as that a greater set of truly available educational options without a doubt expands the individual's freedom of choice and action (Malhotra and Schuler 2005).

$(+2)$ Another argument states that biotechnological improvements allow an individual to free him- or herself from the contingent preconditions that hinder the development of his or her own abilities - and thus the chances of being successful in life. This argument rests on the empirical insight that many of the factors (sometimes inauspicious) that shape our lives are not in our individual control; e.g. the social environment the individual is born into has varying effects on the person's cognitive and emotional development. Yet if improvement measures are available, a person can use them to correct some of the prior disadvantageous influences to purposefully and deliberately influence his or her abilities. Now the exercise of control over one's own action and conduct represents a necessary condition for autonomous decisions. Hence, it is concluded, the (self-determined) use of biotechnological improvement measures to overcome prior negative conditions favours the exercise of freedom, since it allows us to overcome unjustified inequalities and limitations (Buchanan et al. 2000).
$(+3)$ However, most arguments that make use of the concept of freedom to bring out the advantages of enhancement techniques refer to freedom of the will and self-determination and not so much to freedom of action. Since the formation of an autonomous will rests on mental abilities, many arguments limit themselves to neuroenhancement procedures, that is, to interventions in the neuronal processes to improve executive functions (Bostrom 2008).

For example, there is an argument that improved cognitive abilities can lead to more rational and in consequence 'freer' decisions and accordingly to 'freer' actions. Someone who makes decisions rationally possesses a set of consistent reasons for action composed of motivating desires and convictions. The central assumption of this argument is that a person with greater cognitive clarity, caused e.g. by attention-increasing medications, is better able to generate such a consistency in the content of their reasons for action (Crone 2006): someone with an increased capacity for attention and greater clarity of thought can more easily critically assess immediate impulses for action (first-order desires) in light of convictions e.g. about the contextual conditions and the possible consequences of the actions, and to choose a motivating desire accordingly and allow it to guide their action (the formation of second-order volitions) ${ }^{2}$. According to this argument, this capability represents an expansion of individual freedom, as it allows the individual to purposefully make a rational decision and thus avoid acting under the dictates of impulses and drives.

$(+4)$ There are similar arguments claiming that enhancement methods such as the use of psychopharmaceuticals when not medically indicated could allow people to be more authentic, i.e. to be 'themselves' to a greater extent (DeGrazia 2004; Kramer 1997; Levy 2011). This view is supported by the assumption that people generally possess a 'genuine' personality, a set of character traits that distinguishes them from other people. This genuine personality, it is assumed, is however not always able to develop freely on its own but gets 'covered over'. The use of psychopharmaceuticals can eliminate these 'superimpositions' and help people towards an authentic, coherent conduct (Juth 2011). Thus the point of the argument is that people have a higher degree of self-determination if with the help of biotechnological enhancement methods they are enabled to recognize their genuine desires, identify with them and guide their action by these desires. ${ }^{3}$

\footnotetext{
${ }^{2}$ For the distinction between first- and second-order volitions cf. Frankfurt 1971 .

3 A somewhat parallel argument is endorsed when discussing the possibility to "morally enhance" people to help them uncover their moral side and overcome their immoral weaknesses (cf. Persson and Savulescu 2011 and a critical discussion in Harris 2011).
} 
$(+5)$ Enhancement interventions could also help overcoming constraints to participating in society. Given that the "natural lottery" endowed individuals differently with cognitive and physical abilities, the use of enhancement technologies could also help to level the playing field and overcome disadvantages that have a negative impact on the exertion of one's freedom (Buchanan et al. 2000). We do no longer have to accept that some are smarter than others and hence take the lead in making decisions for all. With the help of enhancement interventions it becomes possible to allow also the less capable to make up their relative impairments and engage freely and on equal terms with those who have been preferred by the natural lottery.

(+6) In an interesting side-line of the moral debate about enhancement interventions from a religious perspective, some have argued that using these means in order to improve and shape human nature would be perfectly in line with a God-willed human capacity for human selfimprovement. ${ }^{4}$ The use of biotechnological means can hence be seen as following the divine command to take responsibility for the human lot. Furthermore a creative human being realises the idea that God created humans in his image: him being a creator, a human being as "imago dei" is meant to be creative and to continue the divine creation.

Arguments against enhancement: constraining or loosing freedom

Besides the above-mentioned positions that see an increase or at least a conservation of human freedom in the use of enhancement technologies, there are many critical arguments that also appeal to notions of freedom. Essentially most of these arguments amount to the claim that the use of enhancement techniques curtails individual freedom or even undermines it entirely.

$(-1)$ One argument expresses doubt that expanding options for action actually brings with it an increase in freedom. The objection made against this optimistic assessment is that the existence of certain new options for action drives individuals to take these options through more or less subtly exercised social pressure. The increasing prevalence of enhancement interventions would lead to increasing pressure to subject oneself to these interventions even for those who personally had decided against the use of biotechnology. For example, if in today's society of achievement one's professional prospects are closely coupled to a certain level of cognitive performance, the individual's choice for or against an enhancement procedure becomes a decision for or against a certain job; thus a quantitative expansion of the number of

\footnotetext{
4 "Responsible creativity is playing human as God intends us to." Peters (2003, 198).
}

options for action can lead to a factual restriction of the (socially acceptable) options. ${ }^{5}$ (Bostrom and Roache 2011).

These sorts of sometimes subtle and sometimes very powerful influences on individual behaviour are not new; they range from the pressure on schoolchildren to dress similarly to the pressure to finally get a cell phone-if one doesn't wish to be excluded from the community. These decisions are made under the influence of external factors in a strong sense. This points to a social dimension of individual freedom of decision. Of course no one disputes that individual decisions are always influenced partly by the particular social environment, but the argument supposes that the new possibilities for biotechnological intervention generate a special type of limitation of our freedom of decision (Greely 2011; Lev 2009; Mehlman 2009).

(-2) Enhancement interventions that are forced upon people represent an obvious limitation of people's freedom, both in its positive and its negative form. They limit the pursuit of one's own aims and they restrict the available options to do so. Even if the danger for such enforcements seems to be relatively small in contemporary Western democracies, ${ }^{6}$ they are frequently mentioned in the debate. ${ }^{7}$ Yet, the diverse possibilities for "eugenic" interventions typically feared in such arguments presuppose the existence of a (quasi-) totalitarian setting and it seems to be the exertion of external force which appears as the primary source of concern here, less the actual enhancement intervention themselves.

The argument runs as follows: even under the assumption that such biotechnological interventions in fact had positive repercussions (whereby it is unclear what standard would underlie such an assessment) and that only interventions with positive repercussions would be carried out, these interventions would still violate the individual's freedom and decision-making competence, if the affected persons have not given their consent to the intervention.

The model of freedom pertinent here sees freedom as self-determination over one's own body and thus over the interventions carried out on that body. The model of informed consent based on this notion of freedom is a high ethical standard in medical ethics, holding that medical interventions are only allowed when the patient has explicitly given his or her informed consent. Exceptions to

\footnotetext{
5 See the discussion whether using cognitive enhancements constitutes cheating, for example in Bostrom and Roache 2011.

6 If at all one could only imagine "liberal eugenics" in this context Agar (2004).

7 Cf. the frequent references to Aldous Huxley's distopian novel Brave New World in the literature (e.g. in The President's Council on Bioethics 2003). However, this is not a well-chosen example to express concern about restrictions for freedom through enhancement, since the biotechnical interventions in the novel aim primarily at decreasing the abilities of some in order to have enough people doing unsatisfying work.
} 
this declaration of consent can only be made under precisely defined conditions, such as when the person's power of judgment has been severely impaired due to mental disturbances; in these cases an attempt is made to determine the will of the affected person through a representative.

Another exception to the requirement of informed consent is the treatment of children (that is, persons who are not yet capable of making decisions). Here as well the aim is to make a decision in the best interests of the children through a representative. However, such therapeutic interventions are performed in the absence of informed consent. Given the understanding of freedom as the absence of coercion that this argument rests on, the question of whether an intervention performed without informed consent is coercive is decided by the question of whether the intervention is in what is guessed to be the best informed interest of the affected person (Manson and O'Neill 2007). Yet there is always the risk that the interventions are carried out based on other people's ideas that do not agree with those of the affected person. And in the absence of informed consent this holds for the procedures carried out on children and grown individuals as well. Both cases would involve insufficient regard for freedom as self-determination over one's own body.

Hence it is concluded that biotechnological optimization measures not based on the explicit consent of the affected individuals should be rejected in principle due to the risk of undermining individual self-determination.

(-3) A further objection against enhancement technologies is that the extreme use of such technologies could lead to a transformation of increased cognitive abilities into limitations of rational abilities. The argument rests on the premise that self-determined and autonomous actions require a sound assessment of the available options for action, which presupposes a certain measure of cognitive and mnemonic abilities: making a justified decision to carry out a certain action means evaluating one's own desires, knowing and weighing various options for action and comparing them against previous experiences. Enhancement technologies can have the aim of boosting the cognitive or mnemonic performance of the human brain and thus might favourably affect this decision-making capacity. However, an extreme increase in cognitive abilities could also lead to a dysfunctional and thus reduced decision-making ability. The argument for this is empirical: for example, Alexandr Luria's studies on the hypermnemonic abilities of his patient " $S$ " show that due to his extremely good memory he was no longer able to forget experiences and impressions. Even trivialities were branded into his memories and thus continually present. This made it impossible for him to make decisions; he was incapable of living his life without external aid (Luria 1968).

This sceptical argument against the extreme use of biotechnological improvement measures focuses on the cognitive foundation of freedom as self-determined authorship of action: a significant increase in mental abilities could, it is feared, compromise the foundation of autonomous actions.

(-4) Another sceptical objection against the use of enhancement techniques focuses on a different aspect of freedom, seeing freedom not as the precondition of rational conduct but as its result. On this view the freedom to do or not do certain things is not just the starting point of all human actions but is at the same time a consequence of prior human efforts. On this account the ability to play piano, for example, or to conduct a complicated surgical operation, is the result of long and painstaking practice and training. Only at the end of this learning process is the individual free in this sense: due to the efforts of the will and long years of practice the person is now able to perform a certain action that he or she would otherwise have been unable to perform. This also holds for certain mental states that are qualified as "free" in a sense, such as "Buddhistic equanimity", which also arises through prior effort and practice. Thus the acquisition of abilities and the achievement of certain mental states are the result of individual efforts. Yet it is argued that the potential use of enhancement technologies render this individual development and self-discipline impossible: there would simply no longer be any necessity for this sort of will-power whereby one achieves certain goals and abilities oneself, if there were a biotechnological "short-cut" to these same goals. Yet this devalues the "freedom" for certain actions formerly won through practice. As the mere results of a technical intervention they are no longer an expression of genuine human freedom (Buchanan 2009). Rather actions based on technical self-optimizations have more of the character of automated processes (Sandel 2007).

$(-5)$ Other arguments see freedom as a precondition for participating with one's fellows in the process of negotiating social rules and norms together (Habermas 1983). Habermas develops an argument against the use of genetic technology for genetic improvements in prenatal individuals within the framework of discourse ethics (Habermas 2003). On his view the possibility that some individuals would possess certain abilities and traits with the aid of biotechnologies leads to an "asymmetric communicative situation" in which we can no longer proceed on the assumption that all individuals participating in the discourse are essentially of the same type. The divergent "prehistory" of those who have been biotechnologically improved and those who haven't been would mean that the participants in the discourse could no longer view 
themselves as basically belonging to the same type. Habermas justifies this by reference to the asymmetry in the individuals' status as ends in themselves that would result: whereas those whose genesis had not been tampered with would exist as ends in themselves, those who owe their existence to the use of biotechnology would exist as the result of others' planned actions. This puts the latter in a subordinate position and they could no longer participate in the negotiation processes of discourse ethics on par with the others.

Hence this argument articulates a fear that the individual freedom of the affected individuals - $\mathrm{a}$ freedom consisting in the equal entitlement to participation in the discoursewill be impaired, as this freedom will be replaced by a "social dependency that, because it is ascriptively anchored, is irreversible", that represents "a foreign body within the reciprocal and symmetrical relations of recognition in a moral and legal community of free and equal persons" (Habermas 2003, pp. 65, our emphasis).

(-6) An additional sceptical argument against biotechnological enhancement interventions rests on a different understanding of freedom, namely as the ability to relate oneself in a meaningful way to all that is beyond one's control, that is to develop respect or even gratitude for "the Given" (Sandel 2007). In light of the contingency of the world, which bears inconveniences and problems for every human life, freedom consists precisely in acting under the condition that we accept these intractable and uncontrollable circumstances.

This idea is found in Christian theological approaches, for example, where the insight into the insufficiency of human knowledge and ability compared to divine omnipotence is interpreted as a free act of self-chosen subordination under a higher power. Now when the contingencies of the life-world are brought under the domain of human planning with the help of biotechnologies, this is a new empowerment for humanity; yet at the same time this prevents humans from freely acquiescing to the divine will. Hence it is concluded that enhancement actions impede our freedom in this sense.

\section{"Freedom": a shifting concept}

This presentation of the arguments for and against enhancement that make use of the notion of freedom looks, in summary, as follows in Table 1.

This line-up suggests a striking symmetry. Each freedom-related type of argument for the use of enhancements seems to correspond to a similar counter-argument categorically rejecting such use. However, it is questionable whether there really is such an argumentative symmetry: does each of the arguments lined up against one another indeed rest on the same premises, do they use the same understanding of "freedom"?
We should first note that the concept of freedom (without additional qualification) is obviously semantically vague and thus can be integrated into various semantic contexts. This is already shown by the distinction between freedom of action and freedom of the will and the dimensions of autonomy and authenticity. Hence there are a variety of conceptions of freedom; and we find this same semantic diversity of "freedom" reflected in the various arguments within the enhancement debate.

One might attempt to systematize the arguments by reducing the different uses of the term "freedom" to a single meaning. However, this might have the consequence that either individual semantic nuances get lost by the wayside, or else that, to prevent this, we would end up with a broad, general and thus rather uninformative formulation. So is there nothing more to say about the so-called arguments from freedom found in the enhancement debates except that they use the concept of freedom in various different senses that can hardly be compared with each other?

Despite this diversity it is possible to classify the various uses of the concept of freedom. For there are several points where we can ascertain a complementary relation between a positive and a negative assessment linked to the particular use of the concept of freedom. Here it is also relevant to ask whether-and if so, to what extent-conceptual or empirical justifications are used for the particular assessment. This can bring out the reasons for the different uses of the concept.

The argument that new options represent an expansion of the freedom of action, formulated in general terms, is largely undisputed. If we understand freedom of action in this sense, the argument $(+1)$ is a perhaps somewhat trivial but nonetheless uncontested argument that the new possibilities of enhancement bring with them an expansion of freedom. Yet what is in dispute is whether these new options for action are primarily to be seen positively as the overcoming of coercive powers that existed previously $(+2)$ or negatively as a new potential for coercing individuals - either indirectly $(-1)$ or directly $(-2)$. Hence the appeal to freedom of action can coincide with a positive and a negative assessment of the enhancement options. The former case involves conceptual argumentation: freedom of action means being able to act without hindrances, that is, having as many options as possible; the latter case draws on an empirical consideration, namely that in real lifenormally - a broader set of options for action may impede individual freedom.

Moreover the assessment of the relevance of possible enhancement actions for the exercise of individual freedom of the will can also vary: some see the use of enhancement techniques positively as favouring the foundations of autonomous decision-making by improving the conditions under 
Table 1 Overview of the freedom-related arguments in the moral assessment of enhancement interventions

\begin{tabular}{ll}
\hline Pro enhancement & Contra enhancement \\
\hline +1. More and new options & -1 . Subtle (social) pressure restricting options \\
+2. Fewer constraints on action & -2 . Direct coercion (no informed consent) \\
+3. Control over second-order volitions & -3. Overburdening through excess information \\
+4. Greater authenticity & -4. No authorship of one's own achievements \\
+5. Level playing field & -5. Asymmetrical communicative situation \\
+6. Theological: realising God-willed capacities & $\begin{array}{l}-6 . \text { Theological: loss of free subordination to divine } \\
\text { plan }\end{array}$ \\
\hline
\end{tabular}

which rational, well-founded, free decisions of the will can be made $(+3)$, while others object that the currently "normal" cognitive set is optimal for decision-making, such that all changes-even increases-in our cognitive powers could ultimately impair our ability to form our will autonomously by disturbing the "equilibrium" that our cognitive capacities require $(-3)$. In both of these cases the assessment rests on empirical considerations.

The influence that enhancement measures could have on individual authenticity, on an individual's personality, is also assessed variously. Whereas some people warn of the dangers of estrangement and point out that the use of biotechnologies undermines one's own sense of merit for one's actions, abilities and traits $(-4)$, others argue that the use of enhancements can significantly help people to find and develop their "own self" $(+4)$. Here we again find contrary assessments of the expected effects of enhancement interventions on whether and how individuals see themselves as authentic; and these contrary assessments also rest on empirical considerations.

Also with regard to the free interaction of individuals on equal terms, the use of enhancement interventions is said to have have both a positive and a negative impact: While some hope that the use of enhancement interventions will help levelling the playing field and allow those less favoured by the "natural lottery" to cooperate with the more lucky on equal terms $(+5)$, others fear that these very interventions make communication on equal terms impossible $(-5)$.

The religiously inspired debate is equally divided: Some hold that the use of enhancement interventions is an expression of hubris and lack of respect for the given $(-6)$ while others have argued that using such means is fulfilling the creative project God has initiated before handing it over to humans themselves who are free to choose how to go on with it $(+6)$.

\section{Conceptual and empirical dimensions of "freedom" in the enhancement debate}

The differences among the arguments for and against enhancement that appeal to freedom have several causes.
They are to be explained by the fact that to some extent the various arguments specify the notion of freedom differently, and also by the fact that empirical considerations, together with conceptual considerations, often play a role in the conclusions.

On this diagnosis it does not seem suitable to speak of a "unified" group of arguments from freedom. This would require that we find a sufficiently unified specification of freedom that could then be differentiated into various facets. However, our examination here has shown that freedom is a multi-dimensional "cluster concept" comprising diverse aspects of which we have identified some without claiming to have offered a comprehensive list. Thus the various discussed senses of the concept of freedom-freedom of action, freedom of the will, decisionmaking freedom-each have their own particular significance for the content of the arguments in the enhancement debate. This is shown by the fact that claims involving various senses of freedom can all be weighed against each other: thus we could easily imagine positively assessing the expansion of freedom of action that comes with the availability of new options for action while at the same time seeing in the extreme manipulation of memory a restriction of the freedom of the will that is to be assessed negatively. The different approaches might be incommensurable but do not for that reason have to be incompatible. Hence the non-trivial specification of a unified "core" turns out to be problematic.

What consequences does it have that we can apply such heterogeneous conceptions of freedom to morally assess enhancement interventions? It is questionable whether there can even be such a thing as clear-cut judgments in such circumstances. In view of the diversity of concepts of freedom it seems that the only suitable judgments are perspective-dependent ones that, moreover, require empirical information for a (provisional) conclusion of the judgment. Thus if we ask, for example, whether the use of memory pills would increase the possibility of self-determined actions, we would first need to examine precisely which increase in memory would produce which sort of improved capacity for judgment. Such fine grained analysis is very different from more general claims about increasing 
freedom or autonomy overall. Since these cases might also force us to account for individual differences, we could hardly expect to arrive at any comprehensive and general judgment; our judgment might only apply to individual cases.

Thus the main result we can take away from the discussion presented here is to note that enhancement actions can have both a positive and a negative influence on human freedom - be it freedom of action or freedom of the will. In each individual case we would have to examine more precisely how concrete enhancement interventions impinge upon the various dimensions of freedom in order to arrive at a sophisticated, conceptually clear and empirically informed judgment. The examples of distinctions within the concept of freedom that we drew here should help to provide some orientation by showing how so-called arguments from freedom are structured and how they work in the enhancement debate.

\section{Conclusion}

The concepts of freedom and autonomy are prevalent in the debate over biotechnological improvements in human abilities and play a central role. It is striking that the concept of freedom gets used in arguments both for and against enhancement techniques, which raises the question of why such a heterogeneous situation emerges. This paper aimed to shed more light on the structure and the implicit presuppositions of so-called arguments from freedom in the moral debate about human enhancement. We saw that the concept of freedom not only is used in various senses, but moreover is often coupled with empirical statements as well. Thus the semantic openness of the concept "freedom" allows for a diverse array of interpretive possibilities through contextual adaptation. The individual arguments usually pick out a specific aspect of the concept of freedom and neglect other senses. Hence the attempt to identify a single general specification of "freedom" compatible with all of its uses would be misguided: it could only result in an insufficiently complex construction unsuited to the phenomenon it intends to analyse and assess. Instead it is best to account for the diverse dimensions of freedom manifested in the arguments in these ethical debates by means of a conceptually explicit and empirically informed analysis. One of the specific characteristics of arguments from freedom is their multi-dimensionality.

Having identified these several dimensions, it nevertheless is possible to rank them according to different degrees of salience. Particularly salient for a discussion of the ethical legitimacy of enhancement interventions in liberal societies will be arguments focusing on the underpinnings of autonomous choices $(+3$ and -1$)$, and basically egalitarian considerations of levelling the playing field in order to remove unjust constraints for some $(+5)$. Other arguments such as direct coercion $(-2)$, seem to be less salient in liberal societies that are per definition societies in which totalitarian coercion does not take place; neither are theologian arguments $(+6$ and -6$)$ particularly salient under liberal conditions, since religious preferences are seen as private choices that are not capable of providing general arguments for all members of a society that is rich in diverse world views.

In liberal societies it is relatively undisputed that the individual underpinnings and the social conditions of choice and decision-making are central elements of human freedom. The ethical debate about the impact of enhancement interventions on freedom should hence first and foremost tackle these dimensions.

Acknowledgments The authors thank Holger Baumann, Oliver Kaftan, Johann Roduit and the anonymous reviewers for the journal for their helpful comments on the paper.

\section{References}

Agar, N. 2004. In defence of human enhancement. Malden, MA: Blackwell.

Agar, N. 2010. Humanity's end: Why we should reject radical enhancement. Cambridge, MA: MIT Press.

Berlin, I. 1969. Two concepts of liberty. In Four essays on liberty, ed. I. Berlin, 118-172. London: Oxford University Press.

Bostrom, N. 2008. Why i want to be posthuman when i grow up. In Medical enhancement and posthumanity, ed. B. Gordijn, and R. Chadwick, 107-137. New York, NY: Springer.

Bostrom, N., and R. Roache. 2011. Smart policy: Cognitive enhancement and the public interest. In Enhancing human capacities, ed. J. Savulescu, R. ter Meulen, and G. Kahane, 138-149. Oxford: Wiley.

Bostrom, N., and A. Sandberg. 2009. Cognitive enhancement: Methods, ethics, regulatory challenges. Science and Engineering Ethics 15: 311-341.

Bostrom, N., and J. Savulescu. 2009. Human enhancement ethics: The state of the debate. In Human enhancement, ed. J. Savulescu, and N. Bostrom, 1-22. Oxford/New York: Oxford University Press.

Buchanan, A. 2009. Human nature and enhancement. Bioethics 23(3): 141-150.

Buchanan, A., D. Brock, N. Daniels, and D. Wikler. 2000. From chance to choice: Genetics and justice. Cambridge, MA: Cambridge University Press.

Carter, I. 2012. Positive and negative liberty. The stanford encyclopedia of philosophy (Spring 2012 Edition). Retrieved from http://plato.stanford.edu/archives/spr2012/entries/liberty-positivenegative/.

Christman, J. 2011. Autonomy in moral and political philosophy. The stanford encyclopedia of philosophy (Spring 2011 Edition). Retrieved from http://plato.stanford.edu/archives/spr2011/entries/ autonomy-moral/.

Crone, K. 2006. Gedächtnispillen: Mögliche Auswirkungen auf das Selbstverständnis von Personen. In No Body is Perfect, ed. J. Ach and A. Pollmann, 233-252. Bielefeld: Transcript.

DeGrazia, D. 2004. Prozac, enhancement, and self-creation. In Prozac as a way of life, ed. C. Elliott, and T. Chambers, 33-47. Chapel Hill, NC: University of North Carolina Press. 
Frankfurt, H. 1971. Freedom of the will and the concept of a person. The Journal of Philosophy 68(1): 5-20.

Greely, H.T. 2011. Of nails and hammers: Human biological enhancement and US Policy Tools. In Enhancing human capacities, ed. J. Savulescu, R. ter Meulen, and G. Kahane, 503-520. Oxford: Wiley.

Habermas, J. 1983. Diskursethik: Notizen zu einem Begründungsprogramm. In Moralbewußtsein und kommunikatives Handeln, ed. J. Habermas, 53-125. Frankfurt: Suhrkamp.

Habermas, J. 2003. The future of human nature. Cambridge: Polity Press.

Harris, J. 2011. Moral enhancement and freedom. Bioethics 25(2): 102-111.

Heilinger, J.-C. 2010. Anthropologie und Ethik des Enhancements. Berlin/New York: de Gruyter.

Juth, N. 2011. Enhancement, autonomy, and authenticity. In Enhancing human capacities, ed. J. Savulescu, R. ter Meulen, and G. Kahane, 34-48. Oxford: Wiley.

Kane, R. 2003. The oxford handbook of free will. Oxford: Oxford University Press.

Kramer, P.D. 1997. Listening to prozac. London/New York: Penguin.

Lev, O. 2009. Will biomedical enhancements undermine solidarity, responsibility, equality and autonomy? Bioethics 25(4): 177-184.

Levy, N. 2011. Enhancing authenticity. Journal of Applied Philosophy 28(3): 308-318.
Luria, A.R. 1968. The mind of a mnemonist: A little book about a vast memory. New York: Basic Books.

Malhotra, A., and S.R. Schuler. 2005. Women's empowerment as a variable in international development. In Measuring empowerment: Cross disciplinary perspectives, ed. D. Narayan, 71-88. Washington, DC: World Bank.

Manson, N.C., and O. O'Neill. 2007. Rethinking informed consent in bioethics. Cambridge, MA: Cambridge University Press.

Mehlman, M.J. 2009. The price of perfection: Individualism and society in the era of biomedical enhancement. Baltimore, MD: The Johns Hopkins University Press.

Parens, E. 1995. The goodness of fragility: On the prospect of genetic technologies aimed at the enhancement of human capacities. Kennedy Institute of Ethics Journal 5(2): 141-153.

Persson, I., \& Savulescu, J. 2011. Getting moral enhancement right: The desirability of moral bioenhancement. Bioethics. doi:10.1111/ j.1467-8519.2011.01907.x.

Peters, T. 2003. Playing god?. London: Routledge.

Sandel, M.J. 2007. The case against perfection: Ethics in the age of genetic engineering. Cambridge, MA: Belknap Press of Harvard University Press.

The President's Council on Bioethics. 2003. Beyond therapy: Biotechnology and the pursuit of happiness. New York: Dana Press. 